Article

\title{
Surface Discharges and Flashover Modelling of Solid Insulators in Gases
}

\author{
Mohammed El Amine Slama ${ }^{1, *}$, Abderrahmane Beroual ${ }^{2}$ (D) and Abderrahmane (Manu) Haddad ${ }^{1}$ (D) \\ 1 Advanced High Voltage Engineering Centre, School of Engineering. Cardiff University, Queen's Buildings \\ The Parade, Cardiff, Wales CF24 3AA, UK; haddad@cardiff.ac.uk \\ 2 Laboratoire Ampère, University of Lyon, 36 Avenue Guy de Collongues, 69130 Ecully, France; \\ abderrahmane.beroual@ec-lyon.fr \\ * Correspondence: slamame@cardiff.ac.uk
}

Received: 25 October 2019; Accepted: 9 December 2019; Published: 28 January 2020

check for updates

\begin{abstract}
The aim of this paper is the presentation of an analytical model of insulator flashover and its application for air at atmospheric pressure and pressurized $\mathrm{SF}_{6}$ (Sulfur Hexafluoride). After a review of the main existing models in air and compressed gases, a relationship of flashover voltage based on an electrical equivalent circuit and the thermal properties of the discharge is developed. The model includes the discharge resistance, the insulator impedance and the gas interface impedance. The application of this model to a cylindrical resin-epoxy insulator in air medium and $\mathrm{SF}_{6}$ gas with different pressures gives results close to the experimental measurements.
\end{abstract}

Keywords: surface discharge; flashover; gas; modelling; pressure; thermal properties

\section{Introduction}

In order to optimize the insulation level for high-voltage components (air insulated substations (AIS), gas insulated substations (GIS) and gas insulated lines (GIL), breakers, overhead lines ... ), a special attention is given to creeping or surface discharges because of the thermal effects and the faults that they can produce by sparking or flashover. Then, the knowledge of the parameters characterizing this kind of discharge is essential to understand the complexity of the mechanisms involved in their development. Thus, it is fundamental to acquire such information to enable building a mathematical model that can help in optimizing the insulation efficiency.

This paper aims to carry out a review of existing models of creeping discharges and to propose an analytical approach for the calculation of flashover voltage of solid insulators in gases under lightning voltage stress.

\section{Review of Surface Discharges and Flashover Models in Gases}

From the insulation viewpoint, the triple junction (metal-gas-solid) constitutes the weakest point in high-voltage equipment. Indeed, when the electric field reaches a critical value, partial discharges (PDs) can be initiated in the vicinity of this region. The increase of the voltage leads these PDs to develop and to transform into surface discharges (creeping discharges) that propagate over the insulator up to flashover [1-4]. In the case of GIS and GIL, the worst case is when insulators (spacer, post-type insulator) are contaminated by metallic particles on their surfaces [5,6].

The physical mechanisms responsible for the surface discharge propagation are still not well known because of the complexity of the phenomena and the interaction of different factors, such as the interaction between the discharges, nature of gas and the proprieties of the solid insulating material, gas pressure, surface charges and pollution (metallic particle), geometrical parameters (insulator shape, electrodes form ... ), etc. Fundamental studies have been conducted to understand the inception and 
propagation of creeping discharges in various gases [7-14]. It appears from the reported results that the phenomena start with corona discharges that evolves into ramified streamers. When the streamer discharge reaches a certain length, a leader channel with streamers at its head appears.

The creeping discharge propagation dynamics in $\mathrm{SF}_{6}$ (sulfur hexafluoride) has been investigated by many researchers [7-11]. Okubo et al. [8] reported that the creeping discharge has the same dynamics as in air (Figure 1). Tenbohlen and Schröder [9] analysed the surface discharge under lightning impulse (LI) voltage with different electrical charges deposition on the insulator surface. Figure 1 illustrates the current waveform from the inception to flashover with different electrical charges on the insulator surface. From Figure 1, some similarities with discharge current propagating in air [13] can be noted: the current increases with the leader elongation until the discharge reaches the critical length. Then, the final jump occurs causing the full flashover.
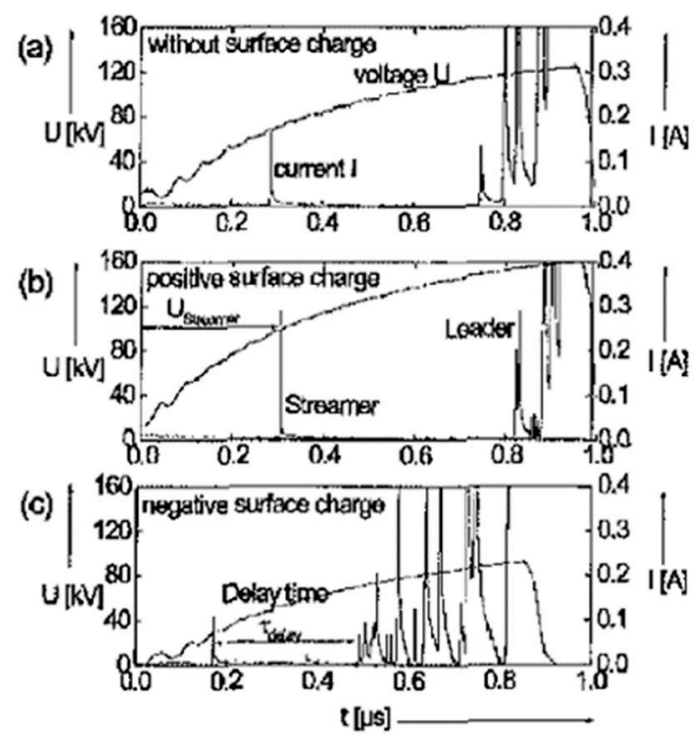

Figure 1. Instantaneous current and voltage during flashover at the surface of cylindrical epoxy insulator according to Reference [9].

Hayakawa et al. [7] analysed the mechanism of impulse creeping discharge propagation on charged PMMA (poly-methyl methacrylate) surface. Their results showed that the discharge propagation is influenced by the charged surface and can be explained by the streamer propagation and streamer-to-leader transition based on the precursor mechanism. On the other hand, according to Okubo et al. [8], Beroual [3] and Beroual et al. [10,11], the creeping discharge propagation depends on the specific capacitance of the solid insulator. The permittivity, the conductivity and the geometry of the insulator affect the propagation of the surface discharge [10-12].

Modelling and calculation of flashover voltage is not an easy task because of the interaction of different parameters, such as gas pressure and its chemical constitution, physicochemical properties of the solid insulator, nature and distribution of the surface charges, etc. Different models have been proposed in order to compute the inception voltage of creeping discharges and flashover voltage of insulator in air at atmospheric pressure $[2,3,13,14]$. Figure 2 depicts the different evolution steps of creeping discharge on the insulator.

According to Reference [2], the corona inception voltage depends on the equivalent capacitance of the system. It can be calculated with the following relationship [2]:

$$
U_{\text {inception }}=\frac{A}{C^{a}}
$$




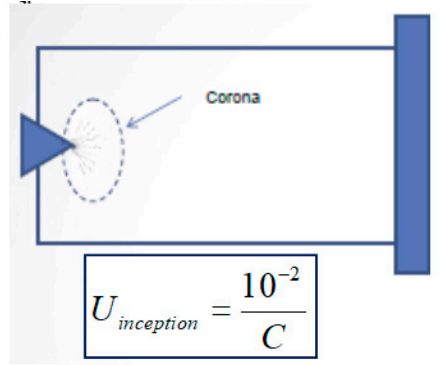

(a): Corona inception

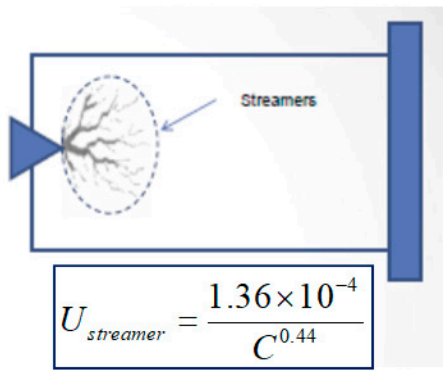

(b): Streamers

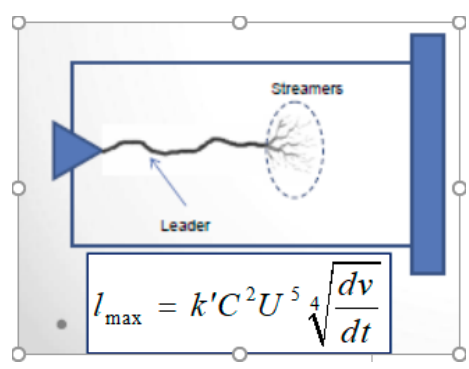

(c): Spark (Streamers/Leader)

Figure 2. Steps of creeping discharges according to Reference [2].

The second step is the appearance of streamers (Figure 2a). The streamers voltage inception is given by [2]:

$$
U_{\text {streamer }}=\frac{B}{C^{b}}
$$

According to Toepler [3], the maximum (critical) length of the discharge that leads to flashover is:

$$
l_{\max }=k \cdot C^{2} \cdot U^{5} \cdot \sqrt[4]{\frac{d u}{d t}}
$$

Then, if the voltage is increased, the discharge will be irreversible and propagates until flashover. In this case, the flashover voltage $U_{f o v}$ can be calculated as well:

$$
U_{f o v}=\frac{D}{C^{d}}
$$

where:

- $C$ is the equivalent capacitance,

- $\quad A, B$ and $D$ are parameters that depend on the geometry and the material of insulator, the kind of the discharge and the experimental conditions (gas, pressure, temperature, humidity, electrodes shape, voltage waveform ... ), respectively. Terms $a, b$ and $d$ are empirical parameters the values of which vary in the range $0.2-0.44$.

These models are empirical and involve only the capacitance of the insulator.

In the case of $\mathrm{SF}_{6}$, Laghari [15] proposed a relationship of flashover voltage based on the efficiency coefficient that represents the ratio of the flashover voltage for uniform electrical gradient distribution to the voltage breakdown of the same gap without an insulator with the same configuration of insulator as well:

$$
V_{f o v}=\frac{12.4}{\ln \left(V_{b}\right)} \cdot \frac{k_{1}}{k_{2}} \cdot \frac{\ln \left(\varepsilon_{r}\right)}{\varepsilon_{r}} \cdot V_{b}
$$

where,

$$
V_{b}=\text { const }+\left(\frac{E}{p}\right)_{c r i} \cdot p \cdot d
$$

$V_{b}$ is the breakdown voltage calculated according to Paschen law. $k_{1}$ and $k_{2}$ are parameters that depend on the roughness and the contact nature between the insulator and the electrodes. $\varepsilon_{\mathrm{r}}$ is the permittivity of the insulator.

Hama et al. [16] proposed a semi-empirical relationship of flashover voltage based on the mechanism leader/precursor:

$$
V_{f o v}=\frac{X_{\text {Leader }}}{D_{\text {pol }} V_{\text {Leader }}}+V_{\text {Leader }}
$$

where $X_{\text {Leader }}$ and $V_{\text {Leader }}$ are the length and the voltage of the leader discharge respectively, and $D_{\text {pol }}$ is a coefficient that is dependent on the polarity of the applied voltage, the reduced critical electrical gradient and the shape of the electrodes, with: 


$$
D_{\text {pol }}=\text { const } \times\left(\frac{E}{p}\right)_{c r i} \times \phi\left(R y_{\text {electrodes }}\right)
$$

The application of this model shows results close to the experimental measurements, but it is limited to the shape of the used insulators and the experimental conditions.

In the following, we recall the main principles of an analytical static model based on the electrical equivalent circuit and thermal discharge temperature we previously developed [1,13].

\section{Principal of Circuit Model}

Surface discharges are like spark (streamer/leader) discharges, i.e., a hot leader column and a streamers zone at its head $[8,9,13,17]$. Based on Figure 3 , the voltage along the discharge can be written as follows:

$$
V_{d}=V_{l}+V_{s}=x_{l} E_{l}+x_{s} E_{s}=x_{d} r_{d} I
$$

where $V_{d}, V_{l}$ and $V_{s}$ are the voltages of the discharge, the leader channel and the streamers, respectively. $x_{1}, x_{s}, E_{l}$ and $E_{s}$ are respectively the length and the electrical gradient of the leader channel and the streamers. $x_{d}, r_{d}$, and I are respectively the discharge length, the discharge resistance and the current.

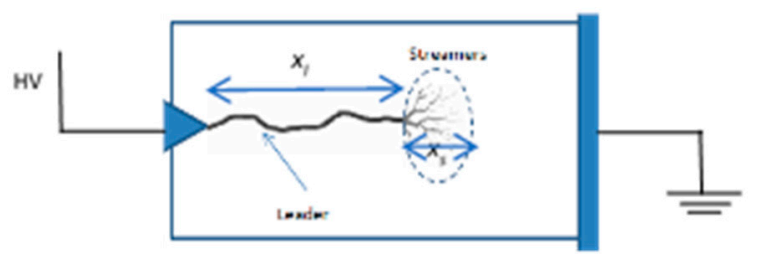

Figure 3. Illustration of leader column and streamers head of a discharge at the surface of an insulator.

The discharge resistance can be deduced from Equation (9):

$$
r_{d}=\frac{x_{l} E_{l}+x_{s} E_{s}}{x_{d} I}
$$

where $x_{d}=x_{s}+x_{l}$.

According to Equation (10), creeping discharge can be considered as a resistance and it can be assumed that the discharge channel is a uniform cylinder.

Many researchers published photos of surface discharges indicating that there are two regions: the main luminous discharge (leader + streamer head) and less luminous branches, as illustrated in Figures 4 and $5[10,18]$. So, the presence of those less luminous discharges can be represented as a resistor in parallel to the insulator surface. On the other hand, several research investigations demonstrate the existence of a dark current in high-pressurized gases that contribute to increase the insulator conductivity [19]. These currents contribute to the appearance of the second region (called luminous plasma), as depicted in Figures 4 and 5.

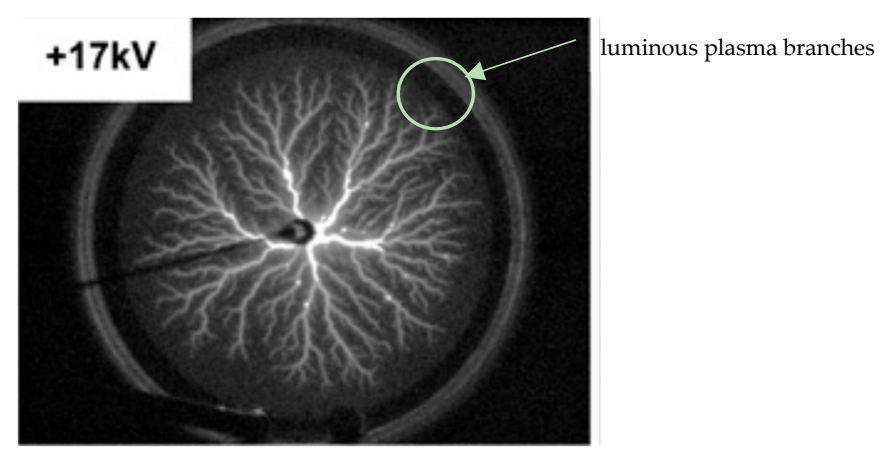

Figure 4. Surface discharge at the surface of insulator in SF6 with 3 bars under LI+ according to Reference [10]. 


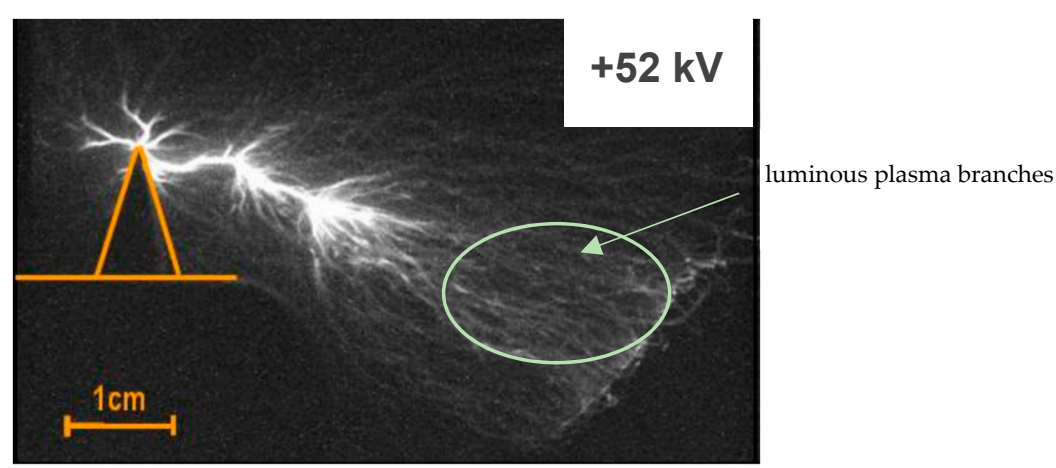

Figure 5. Surface discharge at the surface of a coated electrode in SF6 with 1 bar under LI+ according to Reference [18].

\subsection{Parameters of the Circuit}

The proposed model is constituted by an equivalent electrical circuit representing the electrical discharge, in series with the unbridged gap. The gap (the distance between the head of discharge and the opposite electrode) consists of a gas layer and of the solid dielectric at the interface (Figure 6). The gas layer is assumed to be equal to the diameter of the discharge channel. This model was developed elsewhere [13] in the case of air at atmospheric pressure and represents the instant when the discharge reaches a maximum length (called critical length) before the final jump [13]. In the following, the same approach [13] will be adopted with the assumption that the LI (lightning impulse) voltage waveform can be considered as a quart-cycle of sine signal with a frequency about $0.3 \mathrm{MHz}$.

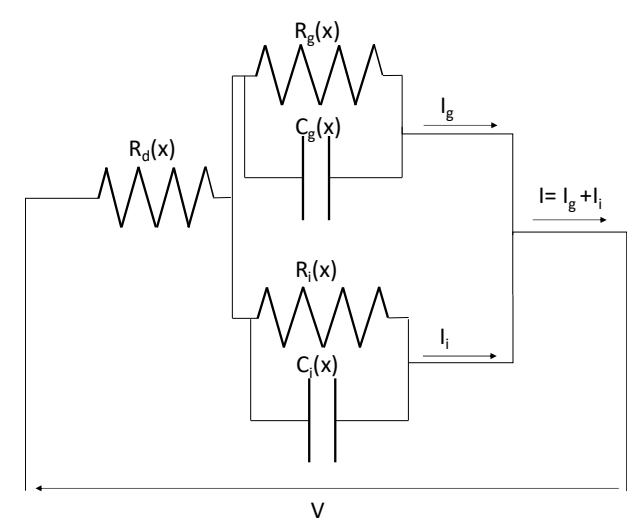

Figure 6. Insulator cylindrical model with a discharge channel and the corresponding equivalent electrical circuit.

The electrical Equation describing this circuit is:

$$
V=R_{d}(x) I+\left[Z_{g}(x) / / Z_{i}(x)\right] I
$$

where,

$$
\begin{gathered}
Z_{g}(X)=R_{g}(x) / / C_{g}(x)=\frac{R_{g}(x)}{1+j \omega R_{g}(x) C_{g}(x)}=\frac{r_{g}(L-x)}{1+\left(r_{g} c_{g} \omega\right)^{2}}-j{\frac{r_{g}{ }^{2} c_{g} \omega(L-x)}{1+\left(r_{g} c_{g} \omega\right)^{2}}}^{2} \\
Z_{i}(X)=R_{i}(x) / / C_{i}(x)=\frac{R_{i}(x)}{1+j \omega R_{i}(x) C_{i}(x)}=\frac{r_{i}(L-x)}{1+\left(r_{i} c_{i} \omega\right)^{2}}-j \frac{r_{i}{ }^{2} c_{i} \omega(L-x)}{1+\left(r_{i} c_{i} \omega\right)^{2}}
\end{gathered}
$$

and

$R_{d}(x)=r_{d} x=x \frac{\rho_{d}}{s_{d}}$

$C_{i}(X)=\frac{c_{i}}{L-x}=\varepsilon_{i} \frac{s_{i}}{L-x} ; C_{g}(X)=\frac{c_{g}}{L-x}=\varepsilon_{g} \frac{s_{g}}{L-x} ; R_{i}(x)=r_{i}(L-x)=\rho_{i} \frac{L-x}{s_{i}} ; R_{g}(x)=r_{g}(L-x)=\rho_{g} \frac{L-x}{s_{g}}$ $r_{d}$ is the linear resistance of the discharge channel. $r_{i}, r_{g}, c_{i}, c_{g}, \varepsilon_{I}, \varepsilon_{g}, \rho_{i}$, and $\rho_{g}$, are respectively the linear resistance, capacitance, the permittivity and the resistivity, respectively of the solid insulator 
and the unbridged gap. $s_{d}$ is the cross-section of the discharge channel, $s_{i}$ and $s_{g}$ are respectively the cross-sections of the solid insulator and the layer of the unbridged gap. $\omega$ is the pulsation $(\omega=2 \pi f$, $f$ being the frequency).

Then, the equivalent impedance of the system will be:

$$
Z_{e q}(x)=r_{d} x+\frac{r_{g} r_{i}}{\alpha_{g} \alpha_{i}} G_{1}(L-x)+j \frac{r_{g} r_{i}}{\alpha_{g} \alpha_{i}} G_{2}(L-x)
$$

Let us put:

$$
\begin{gathered}
\tau_{g}=\rho_{g} \varepsilon_{g} \omega=r_{g} c_{g} \omega \\
\tau_{i}=\rho_{i} \varepsilon_{i} \omega=r_{i} c_{i} \omega
\end{gathered}
$$

Product $\tau_{i}^{2}>>1$ and $\tau_{g}{ }^{2}>>1$, then:

$$
\left\{\begin{array}{c}
\alpha_{i} \approx \tau_{i}^{2} \\
\alpha_{g} \approx \tau_{g}^{2}
\end{array}\right.
$$

The terms $G_{1}$ and $G_{2}$ are:

$$
\begin{aligned}
G_{1} & =\frac{z_{1}}{z_{3}+z_{4}} \\
G_{2} & =\frac{z_{2}}{z_{3}+z_{4}}
\end{aligned}
$$

where,

$$
\left\{\begin{array}{l}
z_{1}=\left(\frac{r_{g}}{\tau_{g}^{2}}+\frac{r_{i}}{\tau_{i}^{2}}\right)\left(1-\tau_{g} \tau_{i}\right)+\left(\frac{r_{g}}{\tau_{g}}+\frac{r_{i}}{\tau_{i}}\right)\left(\tau_{g}+\tau_{i}\right) \\
z_{2}=\left(\frac{r_{g}}{\tau_{g}}+\frac{r_{i}}{\tau_{i}}\right)\left(1-\tau_{i}\right)-\left(\frac{r_{g}}{\tau_{g}^{2}}-\frac{r_{i}}{\tau_{i}^{2}}\right)\left(\tau_{g}+\tau_{i}\right) \\
z_{3}=\left(\frac{r_{g}}{\tau_{g}^{2}}+\frac{r_{i}}{\tau_{i}^{2}}\right)^{2} \\
z_{4}=\left(\frac{r_{g}}{\tau_{g}}+\frac{r_{i}}{\tau_{i}}\right)^{2}
\end{array}\right.
$$

The square of the modulus of the equivalent impedance is:

$$
\left|Z_{e q}\right|^{2}=\gamma x^{2}+2 L x\left[r_{d}\left(r_{d}-\frac{r_{g} r_{i}}{\tau_{g}^{2} \tau_{i}^{2}} G_{1}\right)-\gamma\right]
$$

where,

$$
\gamma=\left(r_{d}-\frac{r_{g} r_{i}}{\tau_{g}^{2} \tau_{i}^{2}} G_{1}\right)^{2}+\left(\frac{r_{g} r_{i}}{\tau_{g}^{2} \tau_{i}^{2}} G_{2}\right)^{2}
$$

According to Reference [20], when the discharge length increases, the equivalent impedance decreases:

$$
\frac{d\left|Z_{e q}\right|^{2}}{d x} \leq 0
$$

By differentiating Equation (18) with respect to $x$, we get:

$$
\frac{d\left|Z_{e q}\right|^{2}}{d x}=2 \gamma x+2 L\left[r_{d}\left(r_{d}-\frac{r_{g} r_{i}}{\tau_{g}^{2} \tau_{i}^{2}} G_{1}\right)-\gamma\right] \leq 0
$$

Then,

$$
\frac{x}{L}-1 \leq\left[\frac{r_{d}}{\gamma \tau_{g}^{2} \tau_{i}^{2}}\left(r_{g} r_{i} G_{1}-\tau_{g}^{2} \tau_{i}^{2} r_{d}\right)\right]
$$

Flashover of the solid dielectric occurs when Equation (22) is equal to zero, i.e., when the discharge length is equal to the total creeping (leakage) distance. This Equation can be considered as "the flashover condition". Therefore, the maximum (or critical) length of the discharge corresponding to flashover is:

$$
x_{c r i}=\frac{L}{\gamma \alpha_{g} \alpha_{i}}\left[\gamma \tau_{g}^{2} \tau_{i}^{2}-r_{d}\left(r_{d}-\tau_{g}^{2} \tau_{i}^{2} G_{1}\right)\right]=L \cdot n
$$


where,

$$
n=\frac{1}{\gamma \tau_{g}^{2} \tau_{i}^{2}}\left[\gamma \tau_{g}^{2} \tau_{i}^{2}-r_{d}\left(r_{d}-r_{g} r_{i} G_{1}\right)\right]
$$

where $0<n<1$.

The worst case can be derived from Equation (12), it corresponds to:

$$
\frac{r_{d}}{\gamma \tau_{g}^{2} \tau_{i}^{2}}\left(r_{g} r_{i} G_{1}-\tau_{g}^{2} \tau_{i}^{2} r_{d}\right) \geq 0
$$

The term $\frac{r_{d}}{\gamma \tau_{g}^{2} \tau_{i}^{2}}$ is always positive, then:

$$
r_{g} r_{i} G_{1} \geq \tau_{g}^{2} \tau_{i}^{2} r_{d}
$$

Equation (26) can be written as:

$$
\frac{\tau_{g}^{2} \tau_{i}^{2}}{G_{1}} \cdot \frac{r_{d}}{r_{g} r_{i}}=K \leq 1
$$

where,

$$
0<K \leq 1
$$

or:

$$
r_{d} \leq K \cdot G_{1} \cdot \frac{r_{g} r_{i}}{\tau_{g}^{2} \tau_{i}^{2}}
$$

Condition (28) indicates that the discharge propagates when the ratio $K$ is less than or equal to 1 . This corresponds to the propagation criterion in which the discharge length is sufficient for causing the final jump, provoking flashover [13].

On the other hand, the power loss per unit length $p_{d}$ in the discharge channel is:

$$
p_{d}=r_{d} I^{2}
$$

By combining Equations (30) and (26), it yields:

$$
I=\sqrt{\frac{p_{d}}{r_{d}}}
$$

The square of the modulus of the voltage-Equation (11) is:

$$
|V|^{2}=|I|^{2} \cdot\left|Z_{e q}\right|^{2}
$$

By substituting Equations (23), (24) and (30) in Equation (18), it yields:

$$
\left|Z_{e q}\right|^{2}=\beta L^{2}\left(\frac{r_{g} r_{i}}{\tau_{g}^{2} \tau_{i}^{2}}\right)^{2}
$$

with:

$$
\beta=K^{2} G_{1}{ }^{2} n^{2}+\left(G_{1}{ }^{2}+G_{2}^{2}\right)(1-n)^{2}+2 K^{2} G_{1} n(1-n)
$$

By substituting Equations (31) and (33) in Equation (32), the Equation of flashover voltage will be deduced as:

$$
V_{F O V}=\frac{L}{\tau_{g} \tau_{i}} \sqrt{p_{d} \cdot \frac{r_{g} r_{i}}{r_{d}} \cdot \beta}
$$

\subsection{Thermal Conductivity and Discharge Resistance}

According to the solution proposed by Frank-Kamenetski [21,22], the energy dissipated by thermal conduction within the discharge channel is:

$$
P_{d}=16 \pi \lambda_{d} \frac{K_{B}}{W_{i}} T^{2}
$$


By combining Equations (36) and (30), the final Equation of flashover voltage will be:

$$
V_{F O V}=4 \frac{L}{\tau_{g} \tau_{i}} T \sqrt{\frac{\pi K_{B}}{W_{i}} \cdot \lambda_{d} \cdot \frac{r_{g} r_{i}}{r_{d}} \cdot \beta}
$$

In the case of air at atmospheric pressure, the thermal conductivity is calculated according to the following Equation [23]:

$$
\lambda(\theta)=\frac{\lambda_{a}}{1+\frac{A_{a}\left(1-v_{a}\right)}{v_{a}}}
$$

where $\lambda_{a}, v_{a}$ and $A_{a}$ are the thermal conductivity, volume fraction and kinetic gas coefficient for air, respectively.

Also, the discharge resistance in air at atmospheric pressure is given by [24]:

$$
r_{d}(T)=r_{0 d} \exp \left(\frac{W_{i}}{2 K_{B} T}\right) .
$$

where $r_{0 d}$ is a constant in the range of operating temperatures of the discharge. $W_{i}$ represents the first ionization energy of the different species constituting the discharge channel and $K_{B}$ is the Boltzmann constant.

In the case of $\mathrm{SF}_{6}$, both discharge resistance and discharge thermal conductivity are functions simultaneously of gas pressure and plasma temperature $[25,26]$.

$$
\begin{aligned}
& \lambda_{d}=\Gamma(T, p) \\
& \sigma_{d}=\Sigma(T, p)
\end{aligned}
$$

According to Pinnekamp and Niemeyer [27], and Niemeyer et al. [28], the temperature of the leader discharge is between $2400 \mathrm{~K}$ and $2800 \mathrm{~K}$. On the other hand, based on the transport parameters data of $\mathrm{SF}_{6}$ published in the literature $[25,26]$, the thermal conductivity was plotted as a function of gas pressure (Figure 7) and the discharge resistance against gas pressure (Figure 8 ) for a range of temperatures between $2500 \mathrm{~K}$ and $3500 \mathrm{~K}$. From these figures, numerical empirical formulae of the discharge thermal conductivity and discharge resistance against pressure for a given temperature was deduced:

$$
\begin{gathered}
\sigma_{d}=A \cdot p^{-m} \\
\lambda_{d}=a_{0}+\ldots+a_{n} p^{n}
\end{gathered}
$$

where $p$ is the gas pressure and $a$ and $A$ are empirical parameters.

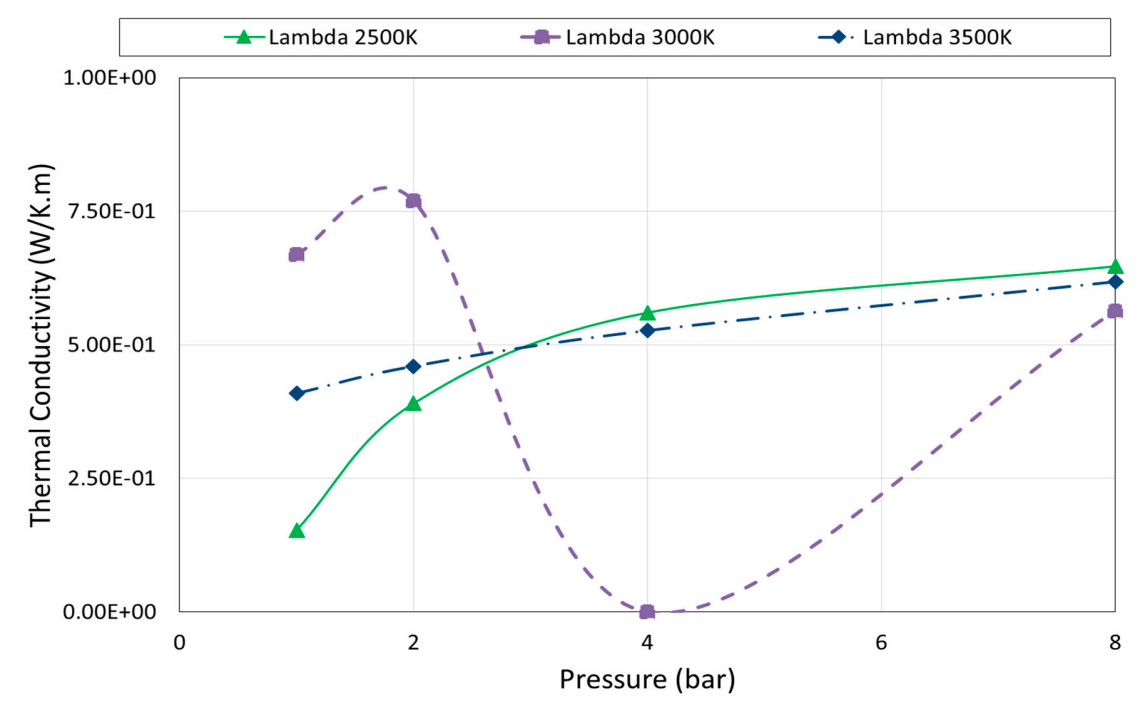

Figure 7. Discharge thermal conductance of discharge versus variation with pressure with for different temperatures. 


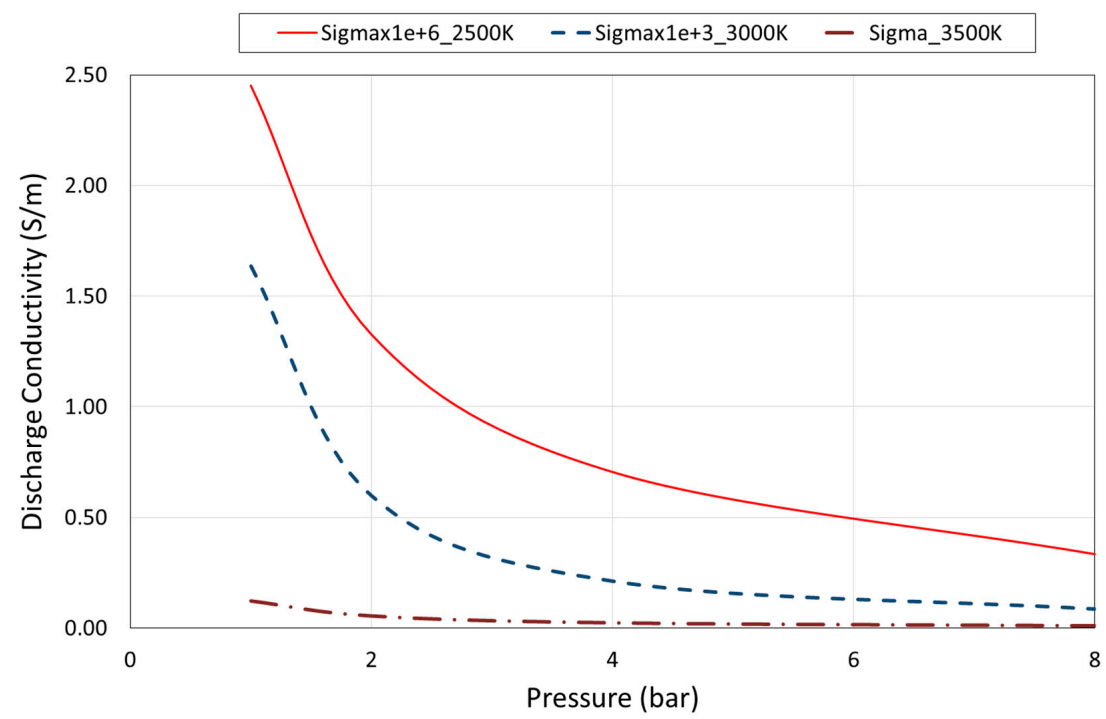

Figure 8. Discharge resistance variation versus pressure with different temperatures at 2500 and $3000 \mathrm{~K}$, respectively.

\section{Application}

To validate the proposed model, first the model was applied for the calculation of the flashover voltage of cylindrical epoxy insulators in air at atmospheric pressure. The second application will be for the same kind of insulator in $\mathrm{SF}_{6}$ gas medium. The computed flashover voltages are compared with the experimental data reported by other researchers, as in References [12,13,15,29]. Table 1 gives the characteristics of the used insulator in the computations.

Table 1. Characteristics of used insulators from literature used in modelling.

\begin{tabular}{ccccccc}
\hline Insulator & Material & Diameter & Length & Reference & Gas & Pressure \\
\hline 1 & Epoxy & 25 & 60 & {$[13]$} & Air & Atmospheric \\
2 & Epoxy & 25 & 60 & {$[12]$} & $\mathrm{SF}_{6}$ & Variable \\
3 & Epoxy & 25 & 45 & {$[29]$} & $\mathrm{SF}_{6}$ & Variable \\
4 & Epoxy & 30 & 10 & {$[15]$} & $\mathrm{SF}_{6}$ & Variable \\
\hline
\end{tabular}

The lightning impulse voltage frequency is calculated based on the following Equation [30]:

$$
f=0.35 / T_{R}
$$

$T_{R}$ is the rising time of the voltage front equal to $1.2 \mu \mathrm{s}$.

\subsection{Air at Normal Atmospheric Conditions}

Figure 9 illustrates the results of the application of the proposed model in air at atmospheric pressure. The model is compared with the experimental data of Reference [13], a previous model developed earlier [1] and Toepler's model. The temperature of discharge was taken between $1800 \mathrm{~K}$ and $2000 \mathrm{~K}$, which corresponds to a leader phase on the insulator surface [13]. The resistance of air ranges from $10^{23}$ to $10^{25} \Omega / \mathrm{cm}$, its dielectric constant being equal to 1 . The effect of humidity and roughness are neglected.

By comparing flashover voltage given by Equation (36) and the other models, we can remark that the computed values are close to the measured ones and follow the same trend. According to this result, we can deduced that the impedance of the interface between the head of the discharge and the opposite electrode plays affects the result (Figure 9). It contributes to the breakdown process before 
the final jump of the discharge (flashover), as described in Reference [12]. The maximum deviation is $18.2 \%$ and the average deviation is less than $5 \%$.

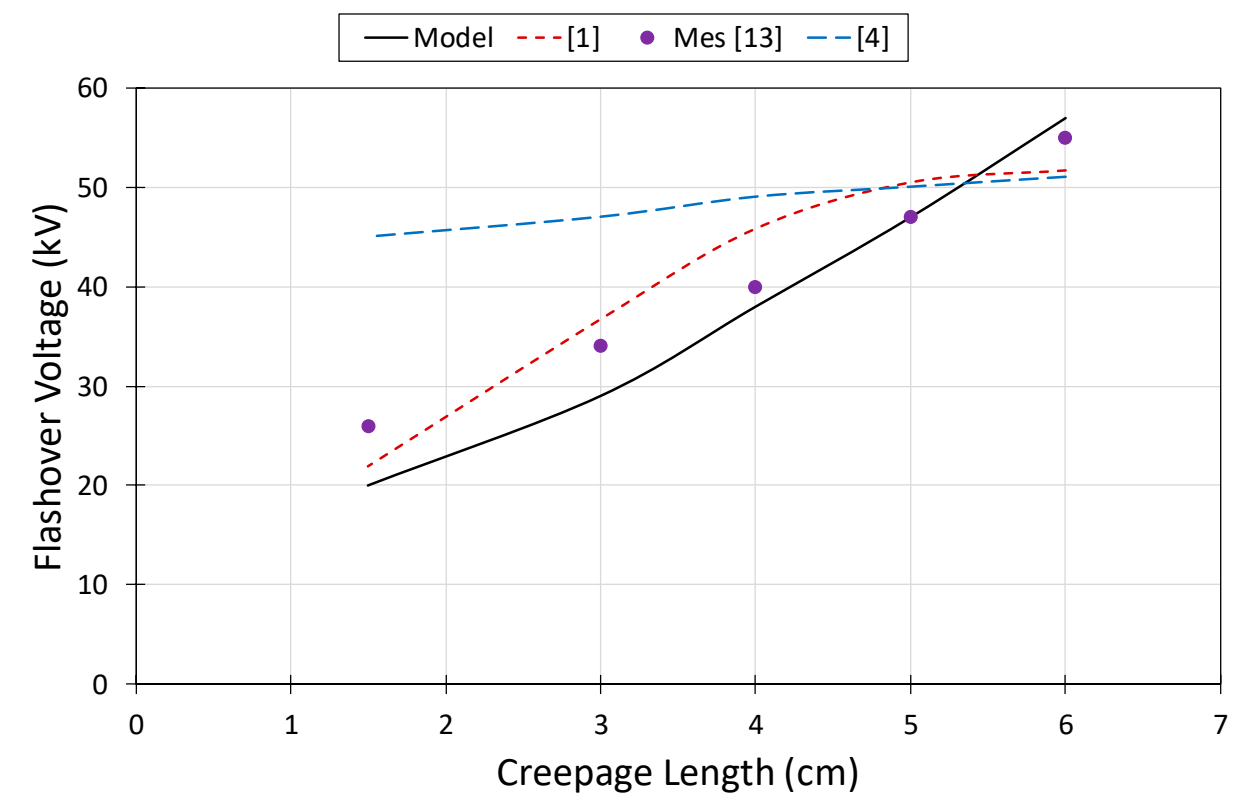

Figure 9. Comparison between calculated and measured flashover voltage versus creepage distance in air at atmospheric pressure for insulator 1.

\section{2. $S F_{6}$ at Variable Pressure}

In the case of $\mathrm{SF}_{6}$, we use Equations (41) and (42), to compute the flashover voltage and its dependency on the gas pressure and temperature. The temperature of the discharge was taken between $2500 \mathrm{~K}$ and $3500 \mathrm{~K}$.

A specific consideration for the resistance of the gas at the interface is required in the case of pressurised $\mathrm{SF}_{6}$. In fact, experimental results concerning flashover of solid insulators on pressurised gases suggest that the discharge tends to stick to the insulator surface when the gas pressure increases [8,12]. On the other hand, according to Figures 4 and 5, the gap between the discharge's head and the ground electrode appears like an ionized cylinder. Knowing that the attachment of the pressurised gas also increases with pressure, it can be deduced that the resistance of the interface between the discharge head and the grounding electrode depends on the gas pressure as well.

Based on the data reported in the literature [25,26], the resistance of the interface can be represented as a cylindrical plasma with a temperature between $1000 \mathrm{~K}$ and $1500 \mathrm{~K}$. In this range of temperature, the plasma resistivity increases with the gas pressure, as depicted in Figure 10. As can be observed in this figure, the assumption of a plasma with a temperature varying between $1200 \mathrm{~K}$ and $1400 \mathrm{~K}$ is a good approximation, since the resistivity is increasing with pressure for all temperatures. The dielectric constant being equal to 1 and the effects of surface charge accumulation and humidity are not considered.

Figure 11 illustrates the comparison of the calculated flashover voltage with the data of Slama et al. [12] for insulator 2 of Table 1. It can be observed that the calculated flashover voltages are close to the measured values, indicating that flashover voltage tends to be stable with the pressure increase. The maximum deviation is $8.2 \%$ and the average deviation is around $4.5 \%$.

A comparison of the calculated flashover voltage with the data of Reference [29] obtained with insulator 3, is depicted in Figure 12. In this work, Moukengué and Feser [29] present results of flashover voltages as a function of gas pressure for different tests: one for a single impulse shot and the second for five impulse shots. It is noted that the calculated flashover voltages are close to the experimental measured values. The maximum deviation is $8.2 \%$ and the average deviation is around $6.5 \%$. 


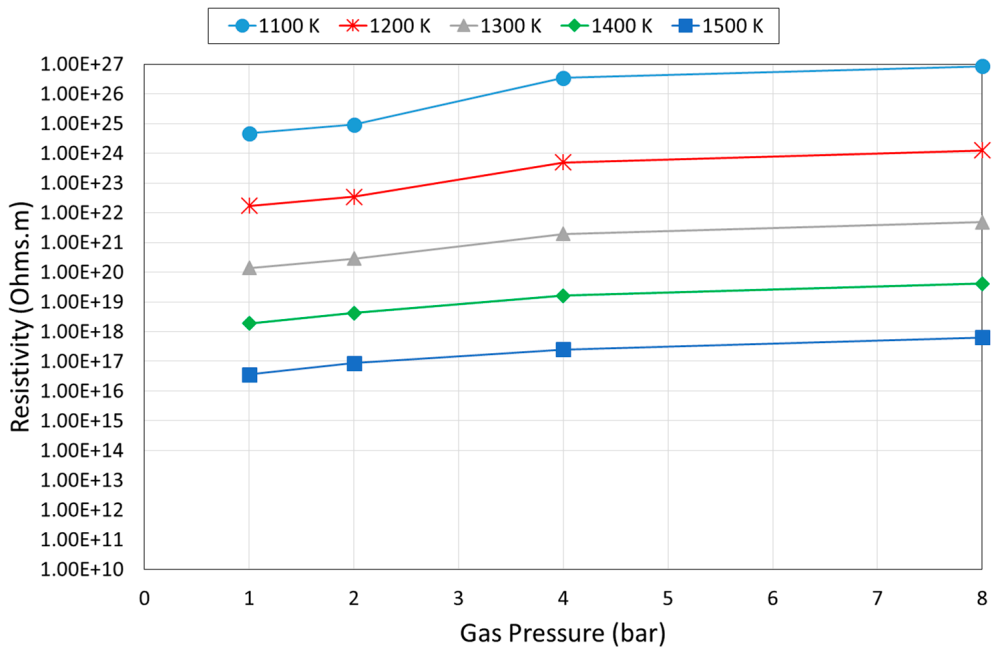

Figure 10. Resistivity of the $\mathrm{SF}_{6}$ plasma at non-thermal regime versus gas pressure et different temperatures.

Epoxy ; $60 \mathrm{~mm}$ Lenght ; $25 \mathrm{~mm}$ Diameter ; Ll+

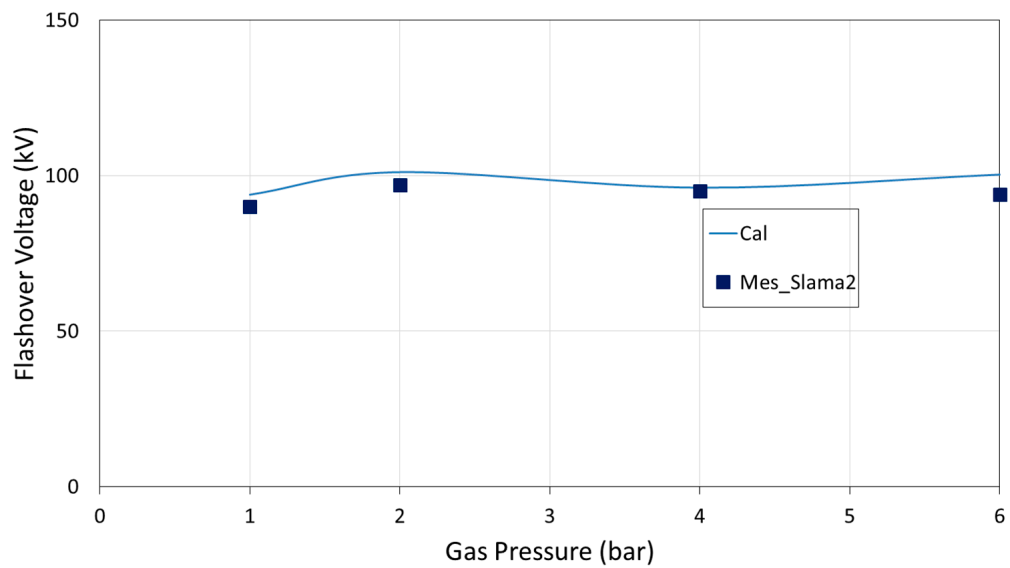

Figure 11. Comparison between calculated and measured flashover voltage versus gas pressure for insulator 2 with $60 \mathrm{~mm}$ length and $25 \mathrm{~mm}$ diameter.

\section{Epoxy ; $45 \mathrm{~mm}$ Lenght ; $25 \mathrm{~mm}$ Diameter ; LI+}

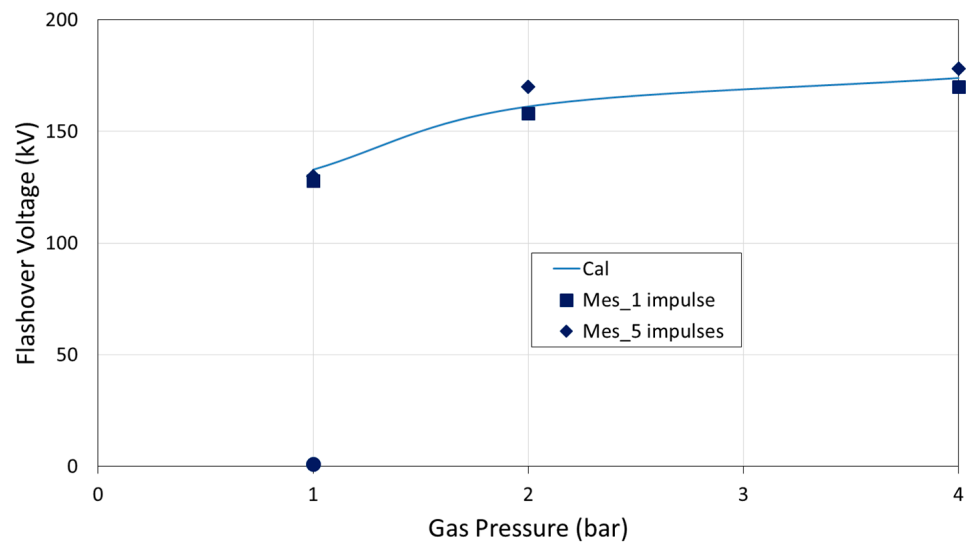

Figure 12. Comparison between calculated and measured flashover voltage versus gas pressure for a cylindrical epoxy insulator 4 with $45 \mathrm{~mm}$ length and $25 \mathrm{~mm}$ diameter. 
Figure 13 shows the comparison of the results using the developed model and the data of Reference [15] with insulator 4. Again, it is observed that the calculated flashover voltages are close to the experimental ones and the maximum deviation is $10 \%$ and the average deviation is less than $4 \%$.

Epoxy ; $10 \mathrm{~mm}$ Lenght ; $30 \mathrm{~mm}$ Diameter ; LI+

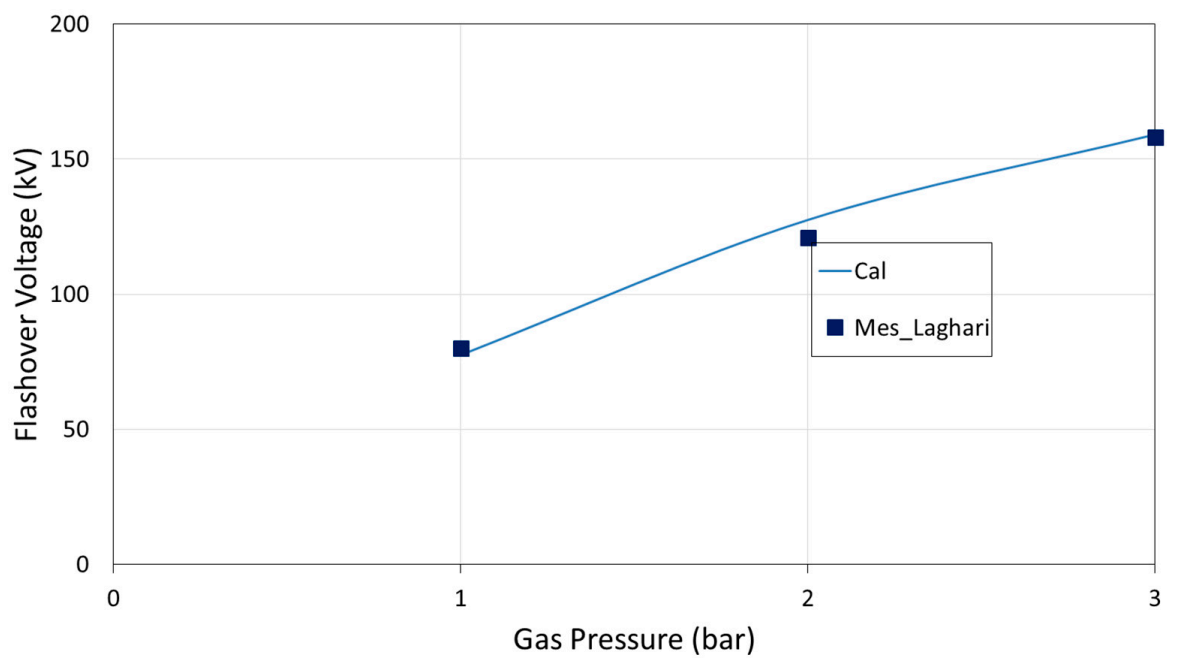

Figure 13. Comparison between calculated and measured flashover voltage versus gas pressure for a cylindrical epoxy insulator with $10 \mathrm{~mm}$ length and $30 \mathrm{~mm}$ diameter.

\section{Conclusions}

In this paper, a model was developed for surface discharges and flashover voltage in air at atmospheric pressure and compressed $\mathrm{SF}_{6}$. The proposed analytical model is based on the equivalent electrical circuit representing the discharge along the insulator surface and the thermal properties of the discharge by assuming that the area between the discharge head and the ground electrode as a cylindrical plasma.

The proposed model was first applied for air at atmospheric pressure to validate it against existing models and data. It was noticed that the simulated results are very close to the experimental ones. Thus, the impedance of the interface between the head of the discharge and the opposite electrode significantly affects the result. It contributes to the breakdown process before the final jump of the final discharge that is flashover. In the case of $\mathrm{SF}_{6}$, the application of this model to various configurations taken from the literature shows that the computed flashover voltage magnitudes are close to the measured values and exhibit similar trends.

The proposed model constitutes a first step for developing a tool for flashover prediction in ambient air and for the design of the solid insulation in GIS and GIL filled with $\mathrm{SF}_{6}$.

Author Contributions: Conceptualization, M.E.A.S., A.B. and A.M.H.; methodology, M.E.A.S., A.B. and A.M.H.; validation, M.E.A.S., A.B. and A.M.H.; formal analysis, M.E.A.S., A.B. and A.M.H.; investigation, M.E.A.S.; writing-original draft preparation, M.E.A.S.; writing-review and editing, M.E.A.S., A.B. and A.M.H.; visualization, M.E.A.S., A.B. and A.M.H. All authors have read and agreed to the published version of the manuscript.

Funding: This research received no external funding.

Acknowledgments: The authors would like to thank Sylvain Nichele, Alain Girodet and Paul Vinson from SuperGrid Institute (France) for their help.

Conflicts of Interest: The authors declare no conflict of interest. 


\section{References}

1. Slama, M.E.A.; Beroual, A.; Girodet, A.; Vinson, P. Characterization and Mathematical Modelling of Surface Solid Insulator in Air. In Proceedings of the International Symposium on High Voltage Engineering, Plzen, Czech Republic, 24-28 August 2015.

2. Al-Arainy, A.B.; Malik, N. Experiments in High Voltage Engineering King, Saud University; Academic Publishing and Press: Riyadh, Saudi Arabia, 2014.

3. Beroual, A. Creeping Discharges at Liquid/solid and Gas/Solid Interfaces: Analogies and Involving Mechanisms. In Proceedings of the IEEE 20th International Conference on Dielectric Liquids (ICDL), Roma, Italy, 23-27 June 2019.

4. Toepler, M. Über die physikalischen Grundgesetze der in der Isolatorentechnik auftretenden elektrischen Gleiterscheinungen. Archiv Elektrotechnik 1921, 10, 157-185. [CrossRef]

5. Cookson, A.H. Review of high-voltage gas breakdown and insulators in compressed gas. IET 1981, 128, 303-312. [CrossRef]

6. Sudarshan, T.S.; Dougal, R. Mechanisms of surface flashover along solid dielectrics in compressed gases: A Review. IEEE Trans. Electr. Insul. 1986, 21, 727-746. [CrossRef]

7. Hayakawa, N.; Ishida, Y.; Nishiguchi, H.; Hikita, M.; Okubo, H. Mechanism of impulse creepage discharge propagation on charged dielectric surface in SF6 gas. IEEJ Trans. Power Energy 1996, 116-B, $600-606$. [CrossRef]

8. Okubo, H.; Kanegami, M.; Hikita, M.; Kito, Y. Creepage Discharge Propagation in Air and SF6 Gas Influenced by Surface Charge on Solid Dielectrics. IEEE Trans. Dielectr. Electr. Insul. 2004, 1, 204-304.

9. Tenbohlen, S.; Schröder, G. Discharge Development over Surfaces in SF6. IEEE Trans. Dielectr. Electr. Insul. 2000, 7, 241-246. [CrossRef]

10. Beroual, A.; Coulibaly, M.-L.; Aitken, O.; Girodet, A. Investigation on creeping discharges propagating over epoxy resin and glass insulators in presence of different gases and mixtures. Eur. Phys. J. Appl. Phys. 2011, 56, 30802-30809. [CrossRef]

11. Beroual, A.; Coulibaly, M.-L.; Aitken, O.; Girodet, A. Effect of micro-fillers in PTFE insulators on the characteristics of surface discharges in presence of $\mathrm{SF} 6, \mathrm{CO}_{2}$ and $\mathrm{SF} 6-\mathrm{CO}_{2}$ mixture. IET Gener. Transm. Distrib. 2012, 6, 951-957. [CrossRef]

12. Slama, M.E.A.; Beroual, A.; Girodet, A.; Vinson, P. Barrier effect on Surface Breakdown of Epoxy Solid Dielectric in SF6 with Various Pressures. In Proceedings of the Conference on Electrical Insulation and Dielectrics Phenomena, Toronto, ON, Canada, 23 October 2016. CEIDP 2016.

13. Slama, M.E.A.; Beroual, A.; Girodet, A.; Vinson, P. Creeping Discharge and Flashover of Solid Dielectric in Air at Atmospheric Pressure: Experiment and Modelling. IEEE Trans. Dielectr. Electr. Insul. 2016, 23, 2949-2956. [CrossRef]

14. Douar, M.A.; Beroual, A.; Souche, X. Creeping discharges features propagating in air at atmospheric pressure on various materials under positive lightning impulse voltage-Part 2: Modelling and computation of discharges' parameters. IET Gener. Transm. Distrib. 2018, 6, 1429-1437. [CrossRef]

15. Laghari, R. Spacer Flashover in Compressed Gases. IEEE Trans. Electr. Insul. 1985, EI-20, 83-92. [CrossRef]

16. Hama, H.; Inami, K.; Yoshimura, M.; Nakanishi, K. Estimation of Breakdown Voltage of Surface Flashover Initiated from Triple Junction in SF6 Gas. IEEJ 1996, 116. [CrossRef]

17. Waters, R.T.; Haddad, A.; Griffiths, H.; Harid, N.; Sarkar, P. Partial-arc and Spark Models of the Flashover of Lightly Polluted Insulators. IEEE Trans. Dielectr. Electr. Insul. 2010, 17, 417-424. [CrossRef]

18. Kessler, J.E.M. Isoliervermögen Hybrider Isoliersysteme in Gasisolierten Metallgekapselten Schaltanlagen (GIS). Ph.D. Thesis, Technische Universität München, Munich, Germany, 2011.

19. Zavattoni, L. Conduction phenomena through gas and insulating solids in HVDC GIS, and consequences on electric field distribution. Ph.D. Thesis, University of Grenoble, Grenoble, France, 2014.

20. Dhahbi-Megriche, N.; Beroual, A.; Krähenbühl, L. A New Proposal Model for Polluted Insulators Flashover. J. Phys. D Appl. Phys. 1997, 30, 889-894. [CrossRef]

21. Fridman, A.; Nester, S.; Kennedy, L.A.; Saveliev, A.; Mutaf-Yardimci, O. Gliding arc discharge. Prog. Energy Combust. Sci. 1999, 25, 211-231. [CrossRef]

22. Fridman, A. Plasma Chemistry; Cambridge University Press: Cambridge, UK, 2008. 
23. McElhannon, W.; McLaughlim, E. Thermal Conductivity of Simple Dense Fluid Mixtures. In Proceedings of the Fourteenth International Conference on Thermal Conductivity, Storrs, CT, USA, 2-4 June 1975; Klemens, P.G., Clen, T.K., Eds.;

24. Slama, M.E.A.; Beroual, A.; Hadi, H. Analytical Computation of Discharge Characteristic Constants and Critical Parameters of Flashover of Polluted Insulators. IEEE Trans. Dielectr. Electr. Insul. 2010, 17, 1764-1771. [CrossRef]

25. Zhong, L.; Rong, M.; Wang, X.; Wu, J.; Han, G.; Lu, Y.; Yang, A.; Wu, Y. Compositions, thermodynamic properties, and transport coefficients of high temperature $\mathrm{C}_{5} \mathrm{~F}_{10} \mathrm{O}$ mixed with $\mathrm{CO}_{2}$ and $\mathrm{O}_{2}$ as substitutes for $\mathrm{SF}_{6}$ to reduce global warming potential. AIP Adv. 2017, 7, 075003. [CrossRef]

26. Assael, M.J.; Koini, I.A.; Antoniadis, K.D.; Huber, M.L.; Abdulagatov, I.M.; Perkins, R.A. Reference Correlation of the Thermal Conductivity of Sulfur Hexafluoride from the Triple Point to $1000 \mathrm{~K}$ and up to $150 \mathrm{MPa}$. J. Phys. Chem. Ref. Data 2012, 41, 023104. [CrossRef]

27. Niemeyer, L.; Pinnekamp, F. Leader discharges in SF6. J. Phys. D: Appl. Phys. 1983, 16, 1031-1045. [CrossRef]

28. Wiegart, N.; Niemeyer, L.; Pinnekamp, F.; Boeck, W.; Kindersberger, J.; Morrow, R.; Zaengl, W.; Zwicky, I.; Gallimberti, M.; Boggs, S.A. Inhomogeneous Field Breakdown in GIS-The Prediction of Breakdown Probabilities and Voltages: Parts I, II, and III. IEEE Trans. Power Deliv. 1988, 3, 923-946. [CrossRef]

29. Moukengué lmano, A.; Feser, K. Flashover behavior of conducting particle on the spacer surface in compressed $\mathrm{N}_{2}, 90 \% \mathrm{~N}_{2}+10 \% \mathrm{SF}_{6}$ and $\mathrm{SF}_{6}$ under lightning impulse stress. In Proceedings of the International Symposium on Electrical Insulation (ISEI 2000), Anaheim, CA, USA, 2-5 April 2000.

30. Ianovici et, M.; Morf, J.-J. Compatibilité Électromagnétique; Presses Polytechniques et Universitaires Romandes: Lausanne, Suisse, 1979.

(C) 2020 by the authors. Licensee MDPI, Basel, Switzerland. This article is an open access article distributed under the terms and conditions of the Creative Commons Attribution (CC BY) license (http://creativecommons.org/licenses/by/4.0/). 